\title{
Observatórios Sociais e sua Importância para a Gestão Pública na Região Sul do Brasil
}

http://dx.doi.org/10.21527/2237-6453.2020.51.113-128

Recebido em: 6/11/2018

Aceito em: 6/9/2019

\section{Jeferson Lopes Goulart, ${ }^{1}$ Alessandra Troian, ${ }^{2}$ Jordy Navarrete Quispe ${ }^{3}$}

\begin{abstract}
RESUMO
O controle social das ações e gastos públicos têm se tornado cada vez mais frequentes no mundo todo. No Brasil, a Constituição Federal de 1988 é o marco deste processo, estabelecendo que o controle da Administração Pública deve ser realizado por órgãos do próprio poder público e pela sociedade. Neste sentido, o presente estudo visa a analisar os benefícios financeiros e os benefícios não financeiros dos Observatórios Sociais (OSs) na Região Sul do país. Metodologicamente foram coletados e analisados os dados presentes no sítio oficial do Observatório Social do Brasil referentes aos Estados do Paraná, Santa Catarina e Rio Grande do Sul, referentes ao ano de 2017. Para tanto, tem-se como principal resultado a indiscutível relevância do papel dos OSs no controle dos gastos públicos. A análise financeira indica economicidade em todos os municípios em questão, variando a porcentagem, mas com significativa economia para os cofres públicos. Já as ações não financeiras, realizadas pelos OSs, giram em torno do acompanhamento das licitações, de reuniões com agentes públicos e a disseminação do controle social por meio de palestras, cursos e capacitações, o que sinaliza o maior conhecimento e controle dos recursos públicos por parte da população.
\end{abstract}

Palavras-chave: Gasto público. Participação. Transparência. Prestação de contas.

\section{SOCIAL OBSERVATORIES AND THEIR IMPORTANCE FOR GOVERNANCE IN SOUTHERN BRAZIL}

\begin{abstract}
The social control of public actions and spending has become more and more frequent all over the world. In Brazil, the Federal Constitution of 1988 is the framework of this process, establishing that the control of Public Administration must be carried out by organs of the public power itself and by society. In this sense, the present study aims to analyze the financial benefits and non-financial benefits of Social Observatories in the southern region of the country. Methodologically, data were collected and analyzed on the official site of the Social Observatory of Brazil for the states of Paraná, Santa Catarina and Rio Grande do Sul, for the year 2017. For this, the main result is the undeniable relevance of the paper control of public spending. The financial analysis indicates economicity in all the municipalities in question, varying the percentage, but with significant savings for the public coffers. The non-financial actions carried out by the OSs revolve around the monitoring of bids, meetings with public agents and the dissemination of social control through lectures, courses and training. This indicates the greater knowledge and control of public resources by the population.
\end{abstract}

Keywords: Public spending. Participation. Transparency. Accountability.

\footnotetext{
${ }^{1}$ Doutor em Ciencias de la Educación pela Universidad Nacional de Rosario, Argentina(UNR). Professor da Universidade Federal do Pampa (Unipampa). jefersongoularte@unipampa.edu.br

${ }^{2}$ Doutora em Desenvolvimento Rural pela Universidade Federal do Rio Grande do Sul (UFRGS). Professora da Universidade Federal do Pampa (Unipampa), Santana do Livramento. alessandratroian@unipampa.edu.br

${ }^{3}$ Acadêmico de Relações Internacionais na Universidade Federal do Pampa (Unipampa). jordynquispe@gmail.com
} 
A Declaração Universal dos Direitos Humanos de 1948, adotada pela Organização das Nações Unidas (ONU), em seu artigo 19, prevê que todos têm direito à liberdade de opinião e de expressão e que este direito inclui a liberdade de expressar opiniões sem interferência e de buscar, receber e transmitir informações e ideias (RIGONI; PARRA, 2017). Neste sentido, visando a buscar e transmitir informações à sociedade, surgiram os Observatórios Sociais (OS) nos Estados Unidos e na Europa Ocidental durante a década de 80 do século 20 (PÉREZ; NASSIF, 2017).

No Brasil, os Observatórios Sociais (OS) ${ }^{4}$ surgiram na década de 90 , com a promulgação da Constituição Federal de 1988, que apresentou a consolidação de importantes movimentos na sociedade brasileira e influenciou o desenvolvimento de observatórios sobre políticas públicas. Isso foi possível por meio das novas leis de acesso à informação, da criação dos Conselhos Gestores das Políticas Públicas e dos mecanismos de participação nos Planos Diretores Municipais (GUEDES; FONSECA, 2010).

A Constituição Federal de 1988 (CF/88), em seu artigo 5ำ, descreve que todos são iguais perante a lei, sem distinção de qualquer natureza, e que todos têm direito a receber dos órgãos públicos informações de seu interesse particular, ou de interesse coletivo. No artigo 37, a Constituição descreve que a Administração Pública obedecerá aos princípios de legalidade, impessoalidade, moralidade, publicidade e eficiência.

A CF/88 estabelece que o controle da Administração Pública deve ser realizado por órgãos do próprio poder público (controle institucional) e pela sociedade (controle social), pois controlar é verificar se a realização de uma determinada atividade atende aos objetivos e às normas para sua execução. Assim, a CF/88, também conhecida como Constituição Cidadã, criou espaços para que o cidadão interessado se aproxime da gestão pública, de modo especial da aplicação dos recursos por ela geridos. A CF/88, em seu artigo 70, descreve que a fiscalização contábil, financeira, orçamentária, operacional e patrimonial será exercida pelos controles externo e interno, estabelecendo, assim, o controle institucional.

Para o avanço da transparência e do controle social, a Lei Complementar no 101/2000, conhecida como Lei de Responsabilidade Fiscal (LRF), em seu artigo 48, descreve que os planos plurianuais, os orçamentos, as leis de diretrizes orçamentárias e as prestações de contas devem ser amplamente divulgadas à sociedade.

A LRF também trouxe o incentivo à participação popular na realização de audiências públicas durante os processos de elaboração e discussão dos planos, lei de diretrizes orçamentárias e orçamentos. Também com a Lei no 12.527/2011, conhecida como a Lei de Acesso à Informação (LAI), em seu artigo 10, descreve que qualquer cidadão poderá apresentar pedido de informação aos órgãos público. Assim, a LAl trouxe o fomento ao desenvolvimento da cultura de transparência e do controle social na Administração Pública.

Neste sentido, para Pérez e Nassif (2017), os Observatórios Sociais compõem sistemas de informações, de comunicação, ambientes de colaboração, segurança de informação e repositórios de dados. Com eles é possível obter informações e gerar conhecimento, cumprindo, dessa forma, o propósito da transparência dos serviços públicos.

${ }^{4}$ No decorrer do texto será utilizada a sigla OS para designar o termo Observatório Social. 
Para tanto, o presente estudo tem como objetivo analisar os benefícios financeiros e os benefícios não financeiros dos Observatórios Sociais na Região Sul do país. Metodologicamente foram coletados e analisados os dados de 2017 presentes no sítio oficial do Observatório Social do Brasil referentes aos Estados do Paraná, Santa Catarina e Rio Grande do Sul.

O estudo justifica-se na medida em que se reconhece a importância do controle social como complementar ao controle institucional, sendo um instrumento de fortalecimento da cidadania. Apesar, porém, dos avanços tanto do lado dos governos, ao se tornarem mais transparentes, quanto da sociedade na busca por informação e participação, o efetivo exercício do controle social não é usual e frequente, além de demandar contingente elevado com disposição para o trabalho voluntário com conhecimentos específicos, uma vez que a atuação do Estado envolve aspectos técnicos, a exemplo da terminologia própria da gestão pública: Plano Plurianual (PPA), Lei de Diretrizes Orçamentária (LDO), Lei Orçamentária Anual (LOA), rubrica, operações de crédito, dívida ativa, dotação orçamentária, empenho, liquidação, restos a pagar, resultado primário e nominal, entre outros.

\section{O SISTEMA DE TRANSPARÊNCIA E O CONTROLE SOCIAL DOS GASTOS PÚBLICOS}

Nesta seção são apresentadas algumas conceituações e estudos sobre a temática da Transparência e da Accountability. Também se discute acerca do Controle e dos Observatórios Sociais. Para tanto, inicia-se fazendo uma discussão sobre o processo democrático, a transparência e a accountability no Brasil.

\section{A Transparência e a Accountability no Setor Público}

As medidas de acesso à informação e transparência são consideradas mecanismos indispensáveis para o fortalecimento da democracia (KREIBIN; ZUCCHI; RAMOS, 2017). Neste cenário destaca-se a ideia de accountability, que, segundo Loureiro e Abrucio (2005), baseia-se nas regras estatais interpessoais fundamentais na área da política econômica, posto que os princípios de restrição orçamentária e expectativas futuras são centrais para as finanças públicas.

Ainda de acordo com Loureiro e Abrucio (2005), no pós-guerra emerge a definição de democracia, a qual pode ser entendida basicamente por três princípios gerais, a saber: a) o governo deve emanar a vontade popular; b) os governos devem prestar contas ao povo; e c) o Estado deve ser regido por normas que delimitem a atuação em prol dos direitos básicos do cidadão. Tais ideários democráticos visam à accountability, a ideia de responsabilidade do poder público perante à sociedade.

Campos (1990) destaca que o conceito accountability ainda não foi compreendido pelos profissionais da Administração Pública e que não se encontra uma tradução literal para o português, fazendo com que o seu uso seja feito no idioma inglês, sendo, muitas vezes, o fator da não compreensão por aqueles que o usam. Pinho e Sacramento (2009), em concordância com Campos (1990), ressaltam que não há uma palavra em português para traduzir a expressão accountability e sim traduções diferentes, originando termos que convergem. 
Para tanto, Raupp e Pinho (2013) afirmam que a expressão accountability demanda a disponibilização pelo poder público das informações de seu desempenho e dos seus resultados, caracterizando, assim, a "prestação de contas". Os autores ainda lembram que a prestação de contas não pode se limitar ao cumprimento da Lei de Responsabilidade Fiscal (LRF) e a Lei de Acesso a Informações (LAI). Ela deve abranger uma análise detalhada sobre a publicização das informações das finanças públicas, e os relatórios da gestão fiscal e balanços orçamentários e contábeis precisam ser apresentados em conjunto e de forma simplificada para a compreensão por todos os cidadãos.

Rocha (2013) afirma que accountability é uma forma de avaliar e responsabilizar os indivíduos portadores de cargos públicos pelo uso do poder a eles conferido pelos cidadãos, além de oportunizar a interação entre os cidadãos e os gestores. Fica evidente que o termo accountability, traduzido para o português como "prestação de contas" e "responsável", não corresponde à totalidade da conceituação aplicada ao Estado brasileiro. Assim, ressalta-se a necessidade da accountability por meio do acompanhamento e fiscalização dos atos praticados pelos gestores públicos.

Neste sentido, para Parreira, Silva e Ramos (2017) as sociedades com pouca transparência na Administração Pública têm mais chances de ter práticas de corrupções e outras formas de utilização dos bens públicos para atingir interesses particulares. Em razão disso, esforços têm sido empregados na tentativa da transparência das ações na gestão pública. Isso melhora o acesso à informação pública e permite a disseminação das informações praticadas na gestão pública.

Cabe lembrar que o Brasil tem uma história democrática curta e recente. Iniciou em 1946 e foi até 1964, mas foi após a redemocratização, em 1984, que os princípios da accountability passam a ser desenhados e a impactarem nas finanças públicas (LOUREIRO; ABRUCIO, 2005). A transparência no Brasil é relativamente atual, tendo como ponto de referência a Constituição Federal da República Brasileira, quando a mesma prevê, em seu artigo 37, os princípios constitucionais: "legalidade, impessoalidade, moralidade, publicidade e eficiências" (BRASIL, 1988). Antes disso, o que prevalecia era a cultura do sigilo no serviço público (RIGONI; PARRA, 2017).

A transparência no setor público brasileiro ganhou importância a partir da edição da Lei Complementar no 101/2000, conhecida como a Lei da Responsabilidade Fiscal (LRF), em especial no artigo 48, que foi ampliado pela Lei Complementar $n=131 / 2009$, que descreve no artigo 48-A:

Para os fins a que se refere o inciso II do parágrafo único do art. 48, os entes da Federação disponibilizarão a qualquer pessoa física ou jurídica o acesso a informações referentes a: I - quanto à despesa: todos os atos praticados pelas unidades gestoras no decorrer da execução da despesa, no momento de sua realização, com a disponibilização mínima dos dados referentes ao número do correspondente processo, ao bem fornecido ou ao serviço prestado, à pessoa física ou jurídica beneficiária do pagamento e, quando for o caso, ao procedimento licitatório realizado; II - quanto à receita: o lançamento e o recebimento de toda a receita das unidades gestoras, inclusive referente a recursos extraordinários (BRASIL, 2000, 2009). 
A transparência dos atos administrativos e das informações públicas são instrumentos essenciais para a gestão pública, que se associam a uma demanda que permita à sociedade uma avaliação da aplicação dos recursos públicos. Neste sentido, a gestão pública conta ainda com a Lei no 12.527/2011, conhecida como Lei de Acesso à Informação, que descreve no artigo 6o:

Cabe aos órgãos e entidades do poder público, observadas as normas e procedimentos específicos aplicáveis, assegurar a: I - gestão transparente da informação, propiciando amplo acesso a ela e sua divulgação; II - proteção da informação, garantindo-se sua disponibilidade, autenticidade e integridade; e III - proteção da informação sigilosa e da informação pessoal, observada a sua disponibilidade, autenticidade, integridade e eventual restrição de acesso (BRASIL, 2011).

De acordo com Medeiros, Magalhães e Pereira (2014), o direito de acesso à informação tem ganhado destaque cada vez maior ao longo dos últimos anos. Sua importância tem sido ressaltada por acadêmicos, especialistas, pela mídia e pelo governo, sendo efetivado com o acesso do cidadão às informações governamentais.

Ainda, tem-se o Decreto № 7.185/2010, que define o padrão mínimo de qualidade do sistema integrado de administração financeira e controle, nos termos do inciso III, parágrafo único, do artigo 48 da LRF. Assim descreve o artigo 2 :

O sistema integrado de administração financeira e controle utilizado no âmbito de cada ente da Federação, doravante denominado SISTEMA, deverá permitir a liberação em tempo real das informações pormenorizadas sobre a execução orçamentária e financeira das unidades gestoras, referentes à receita e à despesa, com a abertura mínima estabelecida neste Decreto, bem como o registro contábil tempestivo dos atos e fatos que afetam ou possam afetar o patrimônio da entidade (BRASIL, 2010a).

O Ministério da Fazenda também editou a Portaria № 548/2010, que estabelece os requisitos mínimos de segurança e contábeis do sistema integrado de administração financeira e controle utilizado no âmbito de cada ente da Federação, adicionais aos previstos no Decreto no 7.185, de 27 de maio de 2010. No artigo 2o descreve: "O SISTEMA deverá possuir mecanismos de controle de acesso de usuários baseados, no mínimo, na segregação das funções de execução orçamentária e financeira, de controle e de consulta". Já no artigo 70 descreve:

O sistema deverá ser desenvolvido em conformidade com as normas gerais para consolidação das contas públicas editadas pelo órgão central de contabilidade da União, relativas à contabilidade aplicada ao setor público e à elaboração dos relatórios e demonstrativos fiscais (BRASIL, 2010b).

O Decreto $n$ ㅇ 7.724/2012, que regulamenta a Lei no 12.527/2011, descreve no artigo 70: "É dever dos órgãos e entidades promover, independente de requerimento, a divulgação em seus sítios na internet de informações de interesse coletivo ou geral por eles produzidas ou custodiadas, observado o disposto nos artigos 7으 e 8음 da Lei no 12.527/2011" (BRASIL, 2012a), determinando, assim, a transparência ativa para a sociedade. 
A Portaria Interministerial no 233/2012 descreve no artigo 10: "Esta Portaria disciplina, no âmbito do Poder Executivo federal, o modo de divulgação da remuneração e subsídio recebidos por ocupante de cargo, posto, graduação, função e emprego público, incluindo auxílios, ajudas de custo, jetons e quaisquer outras vantagens pecuniárias, bem como proventos de aposentadoria e pensões daqueles que estiverem na ativa, conforme disposto no inciso VI do § 3ㅇ do artigo 70 do Decreto $\mathrm{n}$ ㅇ 7.724, de 16 de maio de 2012" (BRASIL, 2012b).

De acordo com Loureiro e Abrucio (2005), a experiência no cenário internacional da Administração Pública evidencia que, quanto maior o controle efetuado pelos cidadãos, mais o Poder Público tem condições de corrigir e melhorar as políticas públicas. Além da existência de mecanismo legais que regem a transparência nos gastos públicos, existem meios de controle social. Assim, visando a ampliar a discussão acerca do papel da sociedade civil no processo de controle dos gastos públicos, a seção a seguir abordará o tema do controle social.

\section{Participação Social na Administração Pública: o Controle e os Observatórios Sociais}

A transparência na Administração Pública no Brasil é incipiente, apesar de, em 1948, a Organização das Nações Unidas ter realizado uma Declaração Universal mencionando que todos têm direto à liberdade de opinião e de expressão, de receber e transmitir informações e ideias. É a partir da redemocratização do Brasil e da promulgação da Constituição Cidadã, no entanto, que se apresenta um cenário propício para a participação popular nas decisões. Para Rigoni e Parra (2017), é a partir da CF/88 que formas de controle social passam a ser criadas e adotadas, como os Conselhos de Políticas Públicas, o orçamento participativo, as ouvidorias públicas e/ou impressa e os Observatórios Sociais.

Mesmo a CF/88 estabelecendo os princípios constitucionais, o serviço público brasileiro era sigiloso até pouco tempo. Com a publicação da LRF e da LAl, o sigilo do serviço público passa de sigilo à publicidade de informações. Assim, cresce a possibilidade de acompanhamento da população a serviços prestados por instituições públicas (RIGONI; PARRA, 2017).

O que é fundamental nesse processo do controle social é a publicidade dos atos administrativos. Tal instrumento é preceito constitucional, isto é, a regra e as exceções concernem às informações em que o "sigilo seja ou permaneça imprescindível à segurança do Estado ou da sociedade" ou que se referem à "inviolabilidade da intimidade, da vida privada, da honra e da imagem das pessoas" (SANTOS, 2017, p. 33). Assim, a Administração Pública busca adaptar-se à realidade da sociedade.

Segundo Coutinho (2000), a Administração Pública voltada para o cidadão adota um sistema de valores democráticos que inicia no Brasil durante a década de 90 do século 20. Os cidadãos passam a compreender melhor que a Administração Pública existe para servi-los, e suas atividades devem ser transparentes e controladas por eles. Os servidores tornam-se, efetivamente, servidores do público, ou seja, o envolvimento dos cidadãos leva os servidores públicos a redefinirem seus papéis e abandonarem suas atitudes autorreferenciadas em favor da prestação de serviços. Nesta perspectiva, 
a Administração Pública orientada para o cidadão retira a imagem negativa que cerca os serviços públicos, estabelecendo um ambiente de apoio e confiança entre Estado e sociedade.

A Administração Pública tenta solucionar os problemas de ineficiência e ineficácia do atendimento, trazendo o cidadão para o centro das suas atenções e preocupações. O conjunto de mudanças no setor público, instituído atualmente por muitos países, tendo em vista as expectativas crescentes da sociedade, concentra-se, então, na figura do usuário. Com isso, uma parte importante dos problemas trazidos à Administração Pública passa a ser resolvida com mais facilidade, olhando mais atentamente para fora das organizações e, consequentemente, para aqueles que usufruem dos seus serviços (COUTINHO, 2000).

Por meio da CF/1988 o Estado brasileiro forneceu importantes instrumentos para o cidadão exercer o controle social. O controle social é feito pela participação popular nas decisões administrativas e é resultante da percepção da efetividade de determinadas ações na vida dos usuários dos serviços. O controle social tem significância na legitimidade do poder dos governantes. Para Ricci,

O conceito de controle social indica, portanto, a participação da sociedade civil na elaboração, acompanhamento e verificação (ou monitoramento) das ações de gestão pública. Na prática, significa definir diretrizes, realizar diagnósticos, indicar prioridades, definir programas e ações, avaliar os objetivos, processos e resultados obtidos (2009, p. 9).

Assim, uma das formas de participação e controle social na Administração Pública são os Observatórios Sociais, que se consolidaram em 2008 com a criação do Instituto da Cidadania Fiscal e que, em 2010, alteraram a denominação para Observatório Social do Brasil. O Observatório Social do Brasil (OSBRASIL) tem como finalidade a atuação no controle social sobre recursos públicos das esferas Federal, Estadual, Distrital e Municipal, bem como a gestão, manutenção e ampliação da Rede de Observatórios Sociais em todo o Brasil (OSBRASIL, 2015).

O Observatório Social é uma associação não governamental formada por voluntários apartidários sem vínculo algum com a Prefeitura e a Câmara da cidade em que atuam. O trabalho dos voluntários nos OSs consiste em monitorar a produção legislativa, difundir a educação fiscal e realizar o acompanhamento dos recursos públicos municipais (PÉREZ; NASSIF, 2017; RIGONI; PARRA, 2017).

Para Albornoz e Herschmann (2006), os Observatórios Sociais têm um ponto comum que é monitorar de forma sistemática o funcionamento ou desempenho de um setor ou tema específico, e costumam coletar, registrar, acompanhar e interpretar dados, produzir indicadores estatísticos, criar metodologias para codificar, classificar e categorizar informações, estabelecer conexões entre pessoas que trabalham em áreas similares, bem como monitorar e analisar tendências.

Assim, os Observatórios Sociais, com base nas informações e análises que produzem, no que se relaciona com a accountability, podem fiscalizar a ação de gestores públicos, contribuir para a observância dos princípios constitucionais da Administração Pública, gerar mobilização coletiva e influenciar decisões e o processo de planejamento, execução e avaliação de políticas públicas (SCHOMMER; MORAES, 2010). 
Para Rigoni e Parra (2017), os Observatórios Sociais atuam em favor da transparência e na correta aplicação dos recursos públicos, reunindo entidades representativas da sociedade civil e os voluntários em um espaço democrático e apartidário. O monitoramento sistemático da gestão pública pelos OS, somado ao comprometimento de voluntários, é fundamental para a eficiência dos atos públicos.

Além disso, o controle social embora não tenha poder para impor sanção direta aos governantes, é efetivo na medida em que influencia ou aciona outros mecanismos institucionalizados de controle e de sansão, como o processo eleitoral e as demais formas de controle durante do mandato - parlamentar, judicial, administrativo e de resultados (SCHOMMER; MORAES, 2010).

Conforme Santos (2017), o Observatório Social, por meio do controle social, visa a contribuir para a melhoria da gestão pública com práticas de cidadania e participação popular, como o monitoramento das licitações e de ações de educação fiscal. Eles têm ainda a função de atuar em favor da transparência e da qualidade na correta aplicação dos recursos públicos, reunindo entidades representativas da sociedade civil e os voluntários em um espaço democrático e apartidário. Os OSs visam a apoiar os gestores públicos para que estes desenvolvam com excelência a prestação de serviços à sociedade, do mesmo modo que possibilitam a participação mais efetiva das pessoas como sociedade civil organizada.

O Observatório Social prima pelo trabalho técnico, fazendo uso de uma metodologia de monitoramento das compras públicas, desde a publicação do edital de licitação até o acompanhamento da entrega do produto ou serviço, de modo a agir preventivamente no controle social dos gastos públicos. Além disso, o OS atua em outras frentes, como na educação fiscal, demonstrando a importância social e econômica dos tributos e a necessidade de o cidadão acompanhar a aplicação dos recursos públicos gerados pelos impostos, na inserção da micro e pequena empresa nos processos licitatórios, contribuindo para geração de emprego e redução da informalidade, bem como aumentando a concorrência e melhorando a qualidade e o preço nas compras públicas, e na construção de Indicadores da Gestão Pública, com base na execução orçamentária e nos indicadores sociais do município, fazendo o comparativo com outras cidades de mesmo porte (OSBRASIL, 2015).

Por fim, sem a pretensão de esgotar o assunto, Santos (2017) analisou o processo vivenciado pelos voluntários do Observatório Social de Marechal Cândido Rondon, no Paraná, visando a identificar a experiência prática de gestão pública participativa realizada por meio da atuação do Observatório Social no município. Como resultados da pesquisa destaca-se que o OS é visto como um instrumento que assegura o controle fiscal da gestão pública local. Segundo o autor, o OSs têm contribuído para a educação e formação de cidadãos conscientes e preocupados com a destinação dos recursos públicos.

Após esta breve discussão teórica sobre os processos democráticos, a transparência e a accountability e o controle social por meio dos Observatórios Sociais, o item a seguir apresenta a metodologia usada no estudo para analisar as contribuições dos OSs na Região Sul do país. 


\section{PROCEDIMENTOS METODOLÓGICOS}

A pesquisa caracteriza-se como descritiva, de abordagem qualitativa. O levantamento de dados acerca dos Observatórios Sociais dos municípios da Região Sul do país foi realizado nos relatórios dos Observatórios Sociais dos Estados do Paraná, Santa Catarina e Rio Grande do Sul, disponíveis no site do Observatório Social do Brasil.

Os relatórios disponíveis são elaborados pelos membros dos Observatórios Sociais com periodicidade quadrimestral, quando são descritas as ações realizadas, e são disponibilizados para a sociedade tomar conhecimento dos resultados da atuação dos OSs. Considerando que nem todos os Observatórios Sociais conseguiram disponibilizar informações referentes aos quadrimestres, para este estudo foram utilizados os relatórios disponíveis no site referentes ao ano de 2017.

Dessa forma, foram analisados 20 OSs dos três Estados da Região Sul do Brasil, a saber: a) nove observatórios no Paraná; b) três em Santa Catarina; e c) oito no Rio Grande do Sul. Cabe destacar que a escolha da Região deu-se por ter sido nela que foi criado o Instituto da Cidadania Fiscal, transformando-se no Observatório Social do Brasil, no Estado do Paraná, em 2010 (OSBRASIL, 2015). A partir do levantamento de dados financeiros e não financeiros, foi realizada a descrição dos valores economizados nas licitações e contratações e também as ações de capacitação, disseminação e conscientização da importância da atuação dos membros do OS.

Em relação aos dados financeiros, a análise consistiu na comparação dos valores orçados nas licitações e contratações. A variável foi escolhida por ser a de maior impacto nos recursos orçamentários e financeiros nos municípios. A partir dos valores homologados e contratados, definiu-se o percentual de economicidade que a atuação dos Observatórios Sociais representou. Ou seja, para calcular o valor economizado foi diminuído o valor orçado do valor licitado.

Acredita-se que os valores economizados representam recursos orçamentários e financeiros que podem ampliar ou melhorar a prestação dos serviços públicos. Ressalta-se que os membros dos OSs costumam analisar as licitações e contratos por meio de amostragem e com base nos gastos mais representativos na utilização dos recursos públicos.

Já os dados não financeiros foram obtidos individualmente em cada observatório social e no site do Observatório Social do Brasil. Foram coletadas as ações realizadas pelos OSs, que também contribuem na melhoria da prestação dos serviços públicos e na transparência da prestação de contas. De posse das informações e ações feitas e publicizadas em cada Observatório Social, realizou-se a padronização dos termos a partir da semelhança do ato. Em seguida, as ações foram categorizadas de modo a apresentar as atividades e identificar quantos OSs têm realizado a atividade de disseminação do controle social.

\section{OBSERVATÓRIOS SOCIAIS:}

\section{Análise dos Dados Financeiros e não Financeiros no Sul do Brasil}

Nesta seção são expostos os resultados da pesquisa. Inicialmente apresenta-se a análise dos dados financeiros e, em seguida, a análise dos dados não financeiros dos OSs. 


\section{Análise dos dados financeiros}

Os Observatórios Sociais podem atuar e contribuir com a gestão pública e também para a disseminação de informações para a sociedade. De acordo com Medeiros, Magalhães e Pereira (2014), o direito de acesso à informação tem ganhado destaque cada vez maior ao longo dos últimos anos. Dessa forma, considerando o atual cenário econômico e político, faz-se necessária uma aplicação eficiente dos recursos, já escassos, na Administração Pública dos municípios. Partindo desse pressuposto, a Tabela 1, a seguir, apresenta os dados financeiros dos Observatórios Sociais, referentes ao ano de 2017, dos Estados que compõem a Região Sul do Brasil.

Tabela 1 - Benefícios financeiros a partir da atuação dos Observatórios Sociais em 2017

\begin{tabular}{|c|c|c|c|c|}
\hline \multirow{2}{*}{ Observatório Social } & \multirow{2}{*}{ Valor Orçado } & \multirow{2}{*}{ Valor Licitado } & \multicolumn{2}{|c|}{ Economicidade } \\
\hline & & & Valor & Percentual \\
\hline \multicolumn{5}{|c|}{ Estado do Rio Grande do Sul } \\
\hline Bento Gonçalves & $19.988 .561,87$ & $13.793 .827,40$ & $6.194 .734,47$ & $30,99 \%$ \\
\hline Caxias do Sul & $28.088 .695,94$ & 26.114.250,69 & $1.974 .445,25$ & $7,03 \%$ \\
\hline Erechim & $55.586 .363,07$ & $50.781 .870,36$ & $4.804 .492,71$ & $8,64 \%$ \\
\hline Guaíba & $9.220 .686,75$ & $5.846 .513,87$ & $3.374 .172,88$ & $36,59 \%$ \\
\hline Novo Hamburgo & $3.482 .800,99$ & $2.242 .612,12$ & $1.240 .188,87$ & $35,61 \%$ \\
\hline Pelotas* & 0,00 & 0,00 & 0,00 & $0,00 \%$ \\
\hline Porto Alegre & $65.133 .415,72$ & $36.203 .473,04$ & $28.929 .942,68$ & $44,42 \%$ \\
\hline São Leopoldo & $3.896 .801,80$ & $3.039 .120,00$ & $857.681,80$ & $22,01 \%$ \\
\hline \multicolumn{5}{|c|}{ Estado de Santa Catarina } \\
\hline Blumenau & $19.266 .966,00$ & $13.739 .468,00$ & $5.527 .498,00$ & $28,69 \%$ \\
\hline Indaial & $6.225 .124,02$ & $4.470 .051,02$ & $1.755 .073,00$ & $28,19 \%$ \\
\hline Morro da Fumaça* & 0,00 & 0,00 & 0,00 & $0,00 \%$ \\
\hline \multicolumn{5}{|c|}{ Estado do Paraná } \\
\hline Assis Chateaubriand & $22.951 .043,63$ & $17.661 .693,32$ & $5.289 .350,31$ & $23,05 \%$ \\
\hline Campos Gerais & $31.076 .904,99$ & $25.627 .555,58$ & $5.449 .349,41$ & $17,54 \%$ \\
\hline Guarapuava* & 0,00 & 0,00 & 0,00 & $0,00 \%$ \\
\hline Irati & $72.926 .437,53$ & $56.763 .522,26$ & $16.162 .915,27$ & $22,16 \%$ \\
\hline Mandaguari & $44.123 .597,13$ & $35.991 .867,39$ & $8.131 .729,74$ & $18,43 \%$ \\
\hline \multicolumn{5}{|l|}{ Marechal Cândido } \\
\hline Rondon* & 0,00 & 0,00 & 0,00 & $0,00 \%$ \\
\hline Medianeira & $39.228 .626,37$ & $29.511 .378,10$ & $9.717 .248,27$ & $24,77 \%$ \\
\hline Paranaguá & $22.473 .937,29$ & $18.966 .469,23$ & $3.507 .468,06$ & $15,61 \%$ \\
\hline
\end{tabular}

* Não foi possível identificar nos relatórios análise de processos de compras públicas.

Fonte: Elaborada pelos autores com base nos relatórios dos Observatórios Sociais de 2017 disponibilizados na página do Observatório Social do Brasil.

A partir dos dados apresentados na Tabela 1, pode-se inferir que o Rio Grande do Sul apresenta os percentuais de economicidade mais elevados nos processos de compras públicas. Quatro dos oito municípios em que o OS atua, apresentam percentuais de economicidade acima de 30\%, com destaque para Porto Alegre, capital do Estado, onde esse índice alcança 44\%. A economicidade nos processos de compras públicas é fundamental para os municípios, uma vez que os orçamentos públicos devem atender às necessidades da sociedade. A economia nas compras públicas representa a possibili- 
dade de ampliar ou melhorar a prestação dos serviços à sociedade. Nesse sentido, Loureiro e Abrucio (2005) mencionam que o orçamento é um instrumento fundamental do governo, pois, por meio dele, os governantes estabelecem prioridades e decidem como gastar os recursos distribuindo entre os diferentes grupos sociais, conforme seu peso e força política.

Já em Santa Catarina apenas dois municípios apresentaram os dados de 2017 das compras públicas, com índice de economicidade de $28 \%$ em cada, o que demostra a baixa participação dos municípios com OS. A baixa participação pode ser explicada em razão de os OSs atuarem com voluntários e dependerem do financiamento de entidades da iniciativa privada. Onde há atuação dos OS, no entanto, tem-se resultados positivos, uma vez que gera economicidade.

No Estado do Paraná, dos seis municípios que apresentaram os dados de 2017, três expõem índices de economicidade acima dos 15\% e três apresentaram índices superiores a $20 \%$. Os resultados são frutos da atuação dos voluntários dos OSs. Conforme Rigoni e Parra (2017), os Observatórios Sociais atuam em favor da transparência e na correta aplicação dos recursos públicos, reunindo entidades representativas da sociedade civil e voluntários em um espaço democrático e apartidário.

Os municípios dos Estados da Região Sul do Brasil têm tamanhos populacionais diferentes e, consequentemente, valores dos orçamentos públicos distintos. A análise dos dados financeiros revela, no entanto, que a economicidade nos processos de compras públicas existe independentemente do tamanho da população do município e do valor do orçamento público.

Assim, a partir dos princípios constitucionais, os OSs atuam em favor da coletividade. Para a atuação, além dos princípios constitucionais, tem-se a LRF, que contribui para a gestão fiscal responsável e transparente dos gestores públicos e, também, a LAI, que confirma o direito de acesso às informações públicas aos cidadãos. Para Schommer e Moraes (2010) os OSs com base nas informações e análises que produzem, podem fiscalizar a ação de gestores públicos e contribuir para a observância dos princípios constitucionais da Administração Pública e também para o processo de planejamento, execução e avaliação de políticas públicas.

Nesse sentido, desde a análise dos dados financeiros realizada pode-se afirmar que, sobretudo a partir dos elevados valores envolvidos nos processos de compras públicas, é extremamente relevante a contribuição dos OSs no que se refere à economicidade. Ou seja, a colaboração dos OSs é inegável para uma gestão mais eficiente dos recursos públicos.

\section{Análise dos dados não financeiros}

Conforme Santos (2017), o Observatório Social, por meio do controle social, visa a contribuir para a melhoria da gestão pública com práticas de cidadania e participação popular, como o monitoramento das licitações municipais e de ações de educação fiscal.

Neste sentido, analisando os dados não financeiros dos OSs, percebe-se que o Paraná é o Estado da Região Sul do Brasil quem tem mais atuação nos OSs, por meio da publicização dos resultados de oito municípios. Em Santana Catarina apenas três municípios informaram as ações de controle social realizadas em 2017. Elas giram em torno 
das licitações, de encontros com agentes públicos e solicitação de informações. Já no Rio Grande do Sul, nove municípios disponibilizaram as atividades realizadas no sentido do controle social no site do Observatório Social do Brasil. Apesar de ser maior em número de municípios participando, as ações dos OSs no Estado do Rio Grande do Sul ainda são incipientes e giram em torno de capacitações internas e reuniões com os agentes públicos.

Os Observatórios Sociais têm desenvolvido diversas ações em prol da eficiência e eficácia dos recursos públicos. Dentre as ações não financeiras dos OSs na Região Sul do Brasil, destaca-se o acompanhamento das licitações, as reuniões com os agentes públicos e servidores e a disseminação do controle social, por meio de palestras, cursos e capacitações. A seguir, no Quadro 1, é possível verificar todas as ações realizadas.

Quadro 1 - Ações não financeiras realizadas pelos Observatórios Sociais do Sul do Brasil: atividade e frequência

\begin{tabular}{|c|l|}
\hline NÚMERO DE OS* & \multicolumn{1}{|c|}{ AÇõES REALIZADAS } \\
\hline 8 & Acompanhar as licitações. \\
\hline 8 & Reunir com agentes públicos e servidores. \\
\hline 7 & Disseminar o controle social (palestras, cursos e capacitações). \\
\hline 4 & Acompanhar as diárias (Legislativo e Executivo). \\
\hline 3 & $\begin{array}{l}\text { Acompanhar a provação dos projetos de lei. } \\
\text { Acompanhar a entrega de produtos (saúde, educação). } \\
\text { Participar de capacitações. }\end{array}$ \\
\hline 2 & $\begin{array}{l}\text { Informar sobre licitações (empresários). } \\
\text { Sugerir melhoramento nos serviços públicos. } \\
\text { Participar das reuniões dos conselhos municipais (saúde, educação, etc.). } \\
\text { Acompanhar a execução de serviços. } \\
\text { Acompanhar a assiduidade dos vereadores. } \\
\text { Participar nas audiências públicas. }\end{array}$ \\
\hline 1 & $\begin{array}{l}\text { Solicitar informações de produtos em estoque (medicamentos). } \\
\text { Verificar a aplicação dos recursos constitucionais em saúde e educação. } \\
\text { Encaminhar denúncias ao Ministério Público. } \\
\text { Acompanhar a execução das obras. } \\
\text { Reunir com outros observatórios. } \\
\text { Solicitar informações. }\end{array}$ \\
\hline 1 & Nenhuma ação realizada. \\
\hline
\end{tabular}

*O número de OS é maior que 20 em razão de os observatórios desenvolverem, de forma geral, diversas ações de controle social. Fonte: Elaborada pelos autores com base nos dados coletados na página do Observatório Social do Brasil (2017).

Como é possível verificar no Quadro 1, dos 20 OSs analisados oito têm realizado o acompanhamento das licitações. Também feitas por oito observatórios aparecem as reuniões com os agentes públicos e os servidores. Já a disseminação do controle social mediante cursos, palestras e capacitações, tem sido desenvolvido por sete observatórios. Percebe-se que o acompanhamento das licitações, as reuniões com agentes envolvidos nas decisões públicas e a disseminação da relevância do controle social, são as principais atividades não financeiras realizadas nos Observatórios Sociais do Sul do 
Brasil. A disseminação do controle social à sociedade contribui para que os cidadãos tenham conhecimento da origem dos recursos públicos e busquem participar na sua aplicação por meio da atuação no controle social, passando a cobrar mais transparência dos agentes públicos na melhoria dos serviços prestados.

Os Observatórios Sociais atuam no controle social dos gastos públicos. Além disso, os observatórios possuem papel preponderante na educação fiscal, demonstrando a importância social e econômica dos tributos e a necessidade de o cidadão acompanhar a aplicação dos recursos públicos gerados pelos impostos, via cursos, capacitações e treinamentos (SCHOMMER; MORAES, 2010; OSBRASIL, 2015). Ou seja, é função dos OSs a articulação entre os atores sociais, atuando no fortalecimento do envolvimento das pessoas para que estas passem a agir no controle dos processos e recursos públicos.

O acompanhamento das diárias do Legislativo e do Executivo é realizado por quatro OSs da Região Sul do Brasil, enquanto o acompanhamento dos projetos de lei, a entrega de produtos licitados e a participação em capacitações são ações desenvolvidas e realizado por três observatórios. Dentre as demais atividades realizadas tem-se o acompanhamento da execução de serviços e da assiduidade dos vereadores.

Destaca-se que o Observatório Social de Novo Hamburgo, na região metropolitana da Porto Alegre, no Rio Grande do Sul, não apresentou nenhuma atividade não financeira. Acredita-se que o observatório não desenvolveu ações de controle social em razão de ser relativamente novo e ainda não estar inserindo as ações desenvolvidas no site do Observatório Brasil. Infere-se, ainda, que o OS não está atuando nos processos licitatórios; possivelmente ele tenha iniciado as atividades por outras áreas, como na análise do quadro de pessoal e na estrutura organizacional, entre outras atividades públicas.

Neste sentido, percebeu-se, a partir da pesquisa, que os Observatórios Sociais do Estado do Rio Grande do Sul, dentre aqueles com informação disponível na página do Observatório Brasil, são os que menos ações de controle social têm desenvolvido. Destaca-se, no entanto, que com maior ou menos atuação os OSs têm papel preponderante na economicidade dos recursos públicos e no controle social, principalmente por intermédio do empoderamento dos atores sociais que têm acesso a informações e a capacitações.

\section{CONSIDERAÇÕES FINAIS}

O presente estudo teve como objetivo analisar os benefícios financeiros e os benefícios não financeiros dos Observatórios Sociais na Região Sul do país. Assim, analisaram-se os dados do ano de 2017 presentes no sítio oficial do Observatório Social do Brasil referentes aos Estados do Paraná, Santa Catarina e Rio Grande do Sul. Para tanto, tem-se como principal resultado a indiscutível relevância do papel dos OSs no controle dos gastos públicos. Os dados analisados indicam economicidade em todos os municípios analisados, variando a porcentagem, mas com significativa economia para os cofres públicos.

A partir das análises realizadas, pode-se perceber que os OSs dos municípios do Estado do Rio Grande do Sul apresentam as maiores porcentagens de economicidade. É no mesmo Estado, no entanto, que foram identificadas poucas ou nenhuma ação não fi- 
nanceira feitas pelos Observatórios Sociais. Por outro lado, no Estado do Paraná é onde mais atividades não financeiras foram realizadas em 2017 pelos OSS, porém, apesar de haver redução dos gastos entre os orçados e os efetivados, as porcentagens de economicidade são as menores dentre os Estados analisados.

As análises das ações não financeiras realizadas pelos Observatórios Sociais da Região Sul do Brasil evidenciam que as atividades giram em torno do acompanhamento das licitações, de reunião com os agentes públicos e da disseminação do controle social por meio de palestras, cursos e capacitações. As ações demonstram a preocupação dos cidadãos com a promoção da transparência e a accountability pelos agentes públicos, uma vez que elas têm focado no controle das licitações e nas capacitações e palestras.

Por fim, uma limitação do estudo foi ter analisado somente os benefícios financeiros referentes aos processos de compras públicas. Complementarmente, porém, foram analisadas as ações realizadas pelos membros dos OSs tratadas como benefícios não financeiros que promovem a disseminação de controle social. Os processos de compras públicas foram de importante análise, pois ficou evidenciado a economicidade nas compras públicas e que podem ser utilizados esses valores para ampliar ou melhorar a prestação dos serviços à sociedade em virtude da atuação do OS.

Considera-se que o estudo pode contribuir para a divulgação e a socialização da importância dos OSs nos municípios e as contribuições que podem trazer para a Administração Pública municipal. Assim, acredita-se que outros estudos possam analisar mais ações realizadas pelos OSs e também ampliar as regiões e, consequentemente, os municípios que dispõem de OS atuando em prol da sociedade e da disseminação do conhecimento para os cidadãos.

\section{REFERÊNCIAS}

ALBORNOZ, L. A.; HERSHMANN, M. Os observatórios ibero-americanos de informação, comunicação e cultura: balanço de uma breve trajetória. E-compós, Revista da Associação Nacional dos Programas de Pós-Graduação em Comunicação, v. 7, p. 1-20, dez. 2006.

BRASIL. Constituição da República Federativa do Brasil. Diário Oficial da União (DOU), Brasília, DF, 5 de outubro de 1988. Disponível em: http://www.planalto.gov.br/ccivil_03/Constituicao/Constituicao.htm. Acesso em: 26 set. 2018.

BRASIL. Lei Complementar no 101, de 4 de maio de 2000. Estabelece normas de finanças públicas voltadas para a responsabilidade na gestão fiscal e dá outras providências. Diário Oficial da União (DOU), Brasília, DF, 5 de maio de 2000. Disponível em: http://www.planalto.gov.br/Ccivil_03/leis/LCP/Lcp101.htm. Acesso em: 26 set. 2018.

BRASIL. Lei Complementar no 131, de 27 de maio de 2009. Acrescenta dispositivos à Lei Complementar no 101, de 4 de maio de 2000. Diário Oficial da União (DOU), Brasília, DF, 28 de maio de 2009. Disponível em: http://www.planalto.gov.br/ccivil_03/LEIS/LCP/Lcp131.htm. Acesso em: 26 set. 2018.

BRASIL. Decreto no 7.185, de 27 de maio de 2010. Dispõe sobre o padrão mínimo de qualidade do sistema integrado de administração financeira e controle, no âmbito de cada ente da Federação. Diário Oficial da União (DOU), Brasília, DF, 27 de maio de 2010a. Disponível em: http://www.planalto.gov.br/ ccivil_03/_Ato2007-2010/2010/Decreto/D7185.htm. Acesso em: 26 set. 2018.

BRASIL. Ministério da Fazenda. Portaria no 548, de 22 de novembro de 2010b. Estabelece os requisitos mínimos de segurança e contábeis do sistema integrado de administração financeira e controle utilizado no âmbito de cada ente da Federação. Disponível em: https://siconfi.tesouro.gov.br/siconfi/pages/public/ conteudo/conteudo.jsf?id=23. Acesso em: 26 set. 2018.

BRASIL. Lei $n$ ㅇ 12.527, de 18 de novembro de 2011. Regula o acesso a informações previsto no inciso XXXIII do art. 5으, no inciso II do § 3으 do art. 37 e no § 2을 do art. 216 da Constituição Federal; altera a Lei no 8.112, de 11 de dezembro de 1990; revoga a Lei no 11.111, de 5 de maio de 2005, e dispositivos da Lei 
no 8.159, de 8 de janeiro de 1991; e dá outras providências. Diário Oficial da União (DOU), Brasília, DF, 18 de novembro de 2011. Disponível em: http://www.planalto.gov.br/ccivil_03/_ato2011-2014/2011/lei/ I12527.htm. Acesso em: 26 set. 2018.

BRASIL. Decreto no 7.724, de 16 de maio de 2012. Regulamenta a Lei no 12.527, de 18 de novembro de 2011. Diário Oficial da União (DOU), Brasília, DF, 18 de maio de 2012a. Disponível em: http://www.planalto.gov.br/ccivil_03/_ato2011-2014/2012/Decreto/D7724.htm. Acesso em: 26 set. 2018.

BRASIL. Portaria Interministerial no 233, de 25 de maio de 2012b. Disciplina, no âmbito do Poder Executivo Federal, o modo de divulgação da remuneração e subsídio recebidos por ocupante de cargo, posto, Graduação, função e emprego público. Disponível em: https://conlegis.planejamento.gov.br/conlegis/legislacao/atoNormativoDetalhesPub.htm?id=898. Acesso em: 26 set. 2018.

CAMPOS, A. M. Accountability: quando poderemos traduzi-la para o português? Revista de Administração Pública, Rio de Janeiro, v. 24, n. 2, p. 30-50, 1990.

COUTINHO, M. J. V. Administração pública voltada para o cidadão: quadro teórico-conceitual. Revista do Serviço Público, v. 51, n. 3, p. 40-73, jul./set. 2000.

GUEDES, Á. M.; FONSECA, F. El control social de la Administración Pública: escenario, avances y dilemas en Brasil. Madrid: Instituto nacional de Administración Pública, 2010. Disponível em: https://www.academia.edu/3596511/El_Control_Social_de_la_Administraci\%C3\%B3n_P\%C3\%BAblica_-_escenario_avances_y_dilemas_en_Brasil. Acesso em: 12 set. 2018.

HOOD, C. The "New Public Manegement" in the 1980's: variations on theme. Accouting, organizations and society, v. 20, n. 2, p. 93-109, 1995.

KLEMANN, M. N. Apoio à produção textual por meio do emprego de uma ferramenta de mineração de textos. 2011. Dissertação (Mestrado em Educação) - Universidade Federal do Rio Grande do Sul, Porto Alegre, 2011.

KREIBIN, M.; ZUCCHI, C.; RAMOS, F. M. Índice de transparência dos portais eletrônicos das Unidades Federativas Brasileiras. In: CONGRESSO INTERNACIONAL DE DESEMPENHO DO SETOR PÚBLICO, 1., 2017, Florianópolis. Anais [...]. Florianópolis, de 4 a 6 de set de 2017.

LOUREIRO, M. R.; ABRUCIO, F. L. Finanças públicas, democracia e accountability. In: BIDERMAN. C.; ARVATE, P. R. (org.). Economia do setor público no Brasil. Rio de Janeiro: Editora Campus, 2005.

MEDEIROS, S. A.; MAGALHÃES, R.; PEREIRA, J. R. Lei de acesso à informação: em busca da transparência e do combate à corrupção. Revista Informação \& Informação, Londrina, v. 19, n. 1, p. 55-75, 2014.

OSBRASIL. Observatório Social do Brasil. Estatuto. 2015. Disponível em: http://osbrasil.org.br/wp-content/uploads/2015/06/OSB_Estatuto-Social-4\%C2\%AA-altera\%C3\%A7\%C3\%A3o.pdf. Acesso em: 26 set. 2018.

PARREIRA, A.; SILVA, A. L. da; RAMOS, C. Transparência, controle social e cidadania, instrumentos de sustentabilidade na sociedade do conhecimento. In: CONGRESSO INTERNACIONAL DE DESEMPENHO DO SETOR PÚBLICO, 1., 2017, Florianópolis. Anais [...]. Florianópolis, Brasil, de 4 a 6 de set. de 2017.

PÉREZ, L. G.; NASSIF, M. E. Fatores de influência na avaliação dos observatórios sociais do Brasil sob a perspectiva da gestão da informação. Revista Informação \& Sociedade, João Pessoa, v. 27, n. 3, p. 31-48, set./dez. 2017.

PINHO, J. A. G.; SACRAMENTO, A. R. S. Accountability: já podemos traduzi-la para o português? Revista de Administração Pública, Rio de Janeiro, v. 43, n. 6, p. 1.332-1.368, nov./dez. 2009.

RAUPP, F. M.; PINHO, J. A. G. Accountability em câmaras municipais: uma investigação em portais eletrônicos. Revista de Administração, Rio de Janeiro, v. 48, n. 4, p. 770-782, 2013.

RIGONI, A. B.; PARRA, P. A transparência como ferramenta de controle social. 2017. Disponível em: http:// osbrasil.org.br/artigos-e-monografias/. Acesso em: 6 out. 2018.

RICCI, R. Controle social: um conceito e muitas confusões. Revista Espaço Acadêmico, n. 98, v. 9, p. 9-12, jul. 2009.

ROCHA, A. C. A realização da accountability em pareceres prévios do Tribunal de Contas de Santa Catarina. Revista Administração Pública, Rio de Janeiro, v. 47, n. 4, p. 901-925, 2013.

SANTOS, G. A. dos. Observatório social e o controle cidadão da gestão pública. 2017. Trabalho de Conclusão de Curso (Bacharelado em Direito) - Universidade Estadual do Oeste do Paraná, Unioeste, Marechal Cândido Rondon, 2017. 
SCHOMMER, P. C.; MORAES, R. L. Observatórios sociais como promotores de controle social e accountability: reflexões a partir da experiência do Observatório Social de Itajaí. Revista Eletrônica de Gestão Organizacional, v. 8, n. 3, p. 298-326, set./dez. 2010.

SELL, F. F.; SAMPAIO, G. L.; ZONATTO, V. C. S.; LAVARDA, C. E. F. Accountability: uma observação sobre o nível de transparência de municípios. In: CONGRESSO INTERNACIONAL DE DESEMPENHO DO SETOR PÚBLICO, 1., 2017, Florianópolis. Anais [...]. Florianópolis, de 4 a 6 de set de 2017. 